\title{
The Feature and Popularization of American Clinical Legal Education
}

\author{
Chen Zhongze ${ }^{1}$,Shi Fang ${ }^{2}$ \\ ${ }^{1}$ Wuhan university of technology,Hongshan District,Wuhan City,Hubei Prov. \\ ${ }^{2}$ Wuhan university of technology,Hongshan District,Wuhan City,Hubei Prov. \\ email:448338373@qq.com.
}

\begin{abstract}
Since clinical legal education rose in the United States, it has profoundly influenced the legal education in numerous countries. This kind of schooling mode makes students majoring in law undertake independently judicial practice and study the critical skills of law practice. Besides, it develops a strong sense of social responsibility and justice of students. For the aspect of popularizing of clinical legal education,we should lay emphasis on how to effectively solve the problems such as raising outlay, broadening the source of cases, providing adequately policy safeguard and implementing dynamically management.
\end{abstract}

Key word: Legal Education; Legal Clinics; Popularization

Legal clinics as a sort of teaching method of law practice have been adopted by plenty of countries. Subsidized by the funds of the FORD, there are dozens of colleges and universities have imported legal clinics education on the basis of conventional legal practice in China since September 2000. It has been proved that legal clinic is a type of instructional mode which agrees with the law of legal practice teaching. And it plays a crucial role in promoting educative reform of combining the theoretical study of law and practical application ability.

\section{The American Clinical Legal Education and its Teaching Features}

Legal clinics education in the United States references the mode which medical students practice in the medical clinics. The legal profession and legal educational circles in the United States just catch sight of the characteristics that medical students who practice in clinics are capable of accepting actual medical matters more comprehensively and enhancing practical ability. Thus, they transplant the medical practice method into legal education and nominate it "Clinical Legal Education".

Dating back to the ancient of clinical legal education, the infancy of it should be in the late 19th and early 20th century. The legal education of apprenticeship has felled into decline at that time. Meanwhile, case system occupied the dominant position which was founded by Langdell who used to be the dean of law school of Harvard University. In the early 20th century, Jerome Frank who was the dean of law school of Yale University led the organization called "Legal Clinics or Dispensaries". He tried to cover the shortage of case system by the means of providing practice opportunities for law students and providing free legal aid for the poor. Furthermore, John Brardewell who was in the Duke University firstly set up "Legal Aid Clinic" in Duke University and University of South Carolina. Numerous universities all followed the example of the "Legal Aid Clinic" soon afterwards. ${ }^{[1]}$

The second momentous stage of clinical legal education is between 1960s and 1970s. The Civil Rights Movement was in vogue at that moment. An increasing number of the poor took up legal weapons and defended their own jus legitimum. In the civil rights movement, lacking of legal sources offered chances and space for the development of clinical legal education of law school. Besides, the FORD Foundation invested substantial contribution into legal clinics. Hence, clinical legal education has been booming well. And since then, it began to influence other countries.

The third stage of clinical legal education is during the last century and it had a new development. Legal clinics accepted broader social affairs than before. It made a breakthrough that not only 
accepted penal and civil scope of agency, but received emerging field, such as human rights, immigrant, environment, community development, etc. Besides, it laid more emphasis on training practical ability of law students.

The advocates of clinical legal education think that the foremost matter that adults learn skills and cultivate qualities is how to learn from experience. The core idea of teaching method of experiential learning is that the fundamental difference between adult learning and child learning lies in that adults are unwilling to accept information passively. They are inclined to acquire knowledge by practicing. And they are apt to learn from the cooperation work with mentors. If someone who intends to master legal practice, especially lawyer affairs, he must be engaged in the actual practical works. This probably is the psychological foundation of the clinical legal education. ${ }^{[2]}$ From the perspective of the legal clinics which were offered by the law school of colleges and universities, such as Harvard University, Yale University and other universities, although there is no fixed and unified model among American legal clinics, however these legal clinics have common point:

Firstly, colleges and universities take the legal clinics as a curriculum to offer. Once law students finish this seminar, he can earn certain credits.

Secondly, legal clinic strives to cultivate law students to be mature learners. And it makes law students learn from experience. Legal clinic is different from the internship programme. The essence of legal clinic lies in it assists law students to develop their experiential learning abilities. Moreover, it helps law students train their reflective abilities by virtue of experience instead of just staying on the aspect of basic skills.

Thirdly, legal clinic is a sort of open educational method. There is no strict system of having classes. And it does not limit the fixed place. The character of teachers in the legal clinic pays more attention to guiding and supervising. They focus on doing suggestive works. Besides, they even can be the members of clinic activities at times. Teachers of legal clinic attend classes without any advance teaching program. Therefore, they do not provide standard answer as well. Students in the legal clinic are able to be opposed to the suggestions that their teachers or even disagree with their teachers. Thereafter, students can take independent actions by their own views.

Fourthly, the teaching contents of legal clinics include elementary skill training, ordinary role playing of court and court debate. But eventually, the trainees of legal clinics are supposed to agent by agreement real cases. And they are obliged to experience complicated fact finding and interpersonal interaction.

Fifthly, clinical legal education is tied up with the legal aid system. The source of cases of clinical legal education is mainly legal aid cases. The design of the project reflects the perfect combination between legal public service and legal practice teaching. ${ }^{[3]}$ It is extremely propitious to shape the professional responsibility and the sense of social justice of students majoring in law that clinical legal education makes students participate in dealing with real cases. In this way, they are trying to solve various complex problems which involve aspects of reality and professional ethics.

Sixthly, the novelty and uniqueness of the teaching method. Such as the Socratic Method, dialogue teaching method, interactive learning, simulated training didactics, case analysis teaching methodology, etc.

\section{The American Clinical Legal Education and its Teaching Features}

Firstly, clinical legal education is capable of motivating the subjective consciousness and initiative of students. Students are the main body and the actual officer of cases in the legal clinics. They are responsible for the litigious parties. Such responsibility is beneficial to develop law students' professional ethics of the legal profession.

Secondly, clinical legal education is conductive to train creativeness of students and exploring ability of legal new knowledge. The cases in the legal clinics no longer are the case analysis questions which have standard answers in advance. The goal of students is not to seek the so-called standard answers any more. It focuses on how to vindicate legal rights for the parties furthest. For students themselves,trying to gain rights for parties is exactly their marks. For this purpose, students do their endeavor to persuade the judges to accept their viewpoints. And this contributes to cultivating the 
creativity of students. Consequently, the standard answers of traditional legal education make little sense for the students which study in legal clinics.

Thirdly, clinical legal education is conductive to developing the "lawyer thought". And it abides by the gradual progress rule of the legal profession. The "lawyer thought" takes the parties of cases into consideration. Its condition is positive. However, the "judge thought" safeguards the dignity of law. Thus, it is in a judicial passivism condition. ${ }^{[4]}$ There are plenty of differences between the two above professions in the aspects like role conception, method of thinking and vocational skill. Traditional education is prone to cultivate the "judge thought". Teacher are accustomed to teaching students that they take the identity of judges. And the answers of case analysis teaching material are mainly rest with the judges to make a case-typing conclusion. There are few trains of the "judge thought". But clinical legal education trains students how to attempt to persuade judges. Accordingly, clinical legal education conforms to realistic growth of domestic legal talents.

Fourthly, clinical legal education conduces to culture the overall quality of students majoring in law. Clinical legal education provides integrated legal services. It exactly exercises various aspects quality of students in the process of receiving parties, investigating and gathering for evidence, cogitating individual cases, reconciling amicable settlement, participating in hearing court and so on. ${ }^{[5]}$ Therefore, the outlook on life, sense of worth and comprehensive quality of students will be greatly raised, especially they firsthand experience justice and feel the forces of law in the process of practice. However, there i s no such function in traditional case teaching.

\section{Popularization Mechanism of Clinical Legal Education in China}

In the promotion of clinical legal education, we should pay attention to the following problems:

Firstly, putting the axe in the helve effectively about funding problems. The basic function of legal clinics is targeting for providing communities with certain legal services. The legal service provided by legal clinics mostly is legal aid. And such circumstance decides that it is difficult to broaden the social financing channel of the legal clinic at least during the initial stage. Thus, clinical legal education could take full advantage of national finance, school fund and social fund. Moreover, clinical legal education can build a fund procurement channel combing the above three aspects.

Secondly, enlarging the source of cases. Students who study in the legal clinics should firstly acquire the legal professional qualification. Next, the source of cases mainly relies on legal aid center. Meanwhile, legal clinics ought to start special websites which include the networking mechanism of all areas legal aid center. And, legal clinics are supposed to maintain well the websites, distribute potential source of cases and expand search of territorial classification. Besides, clinical legal education should explain problems online and accept business of community legal advice at fixed period. And it ought to persevere in the new pattern which is "going out and coming in". Besides, it should enlarge the source of cases in multiple perspectives and different levels.

Thirdly, offering sufficient policy safeguards. Universities are supposed to formulate relevant evaluation and incentive mechanism. Meanwhile, they should establish the assessment system. Besides, once clinical legal education relies on administrative means to popularize and safeguard, it can lay down rules or opinions by administrative department of education and legal education committee. Moreover, legal clinics generalize such policy in colleges and universities. At the same time, legal clinics make such popularization normalize and standardize. Simultaneously, legal clinics seek supports of office departments like court and social circles to gain recognition.

Fourthly, implementing dynamic management. Legal clinics are supposed to build an institution which is able to put the source of cases into files during the management period following the example of court. Besides, legal clinics practice selection system. Students openly inquire the cases by using the campus network and write preliminary agent reports. And then, special review board which is set up by clinical teachers conducts selection in case of synthesizing various reports. And they allocate the sources of cases to students according to analyzing physical truth. Meanwhile, legal clinics encourage students to agent cases together by teamwork. Students receive persons who come to consult legal matters in the clinics regularly. All things being equal, their optimal agents are the persons who are received firstly by students in principle. After finishing cases, legal clinics should 
establish complete records. All the written materials forming in the process of agent are needed to be uploaded in the case files regularly, such as plaint, evidence list and statement of the agent. It not only is convenient for putting on records and searching cases, but will be important indicators for performance check and evaluation as well. Establishing a mechanism of rotation and cohesion after finishing agent cases: it should be centered on the recommendation of the original student agent, with independent check and evaluation subsidiary. And this could safeguard the right which the case agent is able to grasp the situation of the case. Moreover, it makes the case agent participate in the whole process of hearing the case, executing the case and winding up the case.

We should cultivate application-based legal personnels as the goal and select educative reform method of law which is the most suitable for the actual situation in China. And popularizing comprehensively the clinical legal education.

\section{References}

[1] Charles R. McManis, The History of First Century American Legal Education: A Revisionist

Perspective, 59 Wash. U. L. Q, (1981) . p. $617-618$.

[2]George S. Grossman, Clinical Legal Education: History and Diagnosis , 26 J. LEGAL EDUC, (1974) . p. $162-165$.

[3]John S. Bradway, The Nature of a Legal Aid Clinic, 3S. Cal. L. Rev, (1930) . p. 174.

[4] William P. Quigley, Introduction to Clinical Teaching for the New Clinical Law Profession; A

View From the First Floor, 28 AKRON L. REV, ( 1995) . p. 465 - 466.

[5]Quintin Johnston, Law School Clinics, 3J. Legal Educ. ( 1951) . P. 535. 